Document downloaded from:

http://hdl.handle.net/10251/157918

This paper must be cited as:

Galindo, J.; Piqueras, P.; Navarro, R.; Tarí, D.; Meano, CM. (2019). Validation and sensitivity analysis of an in-flow water condensation model for 3D-CFD simulations of humid air streams mixing. International Journal of Thermal Sciences. 136:410-419. https://doi.org/10.1016/j.ijthermalsci.2018.10.043

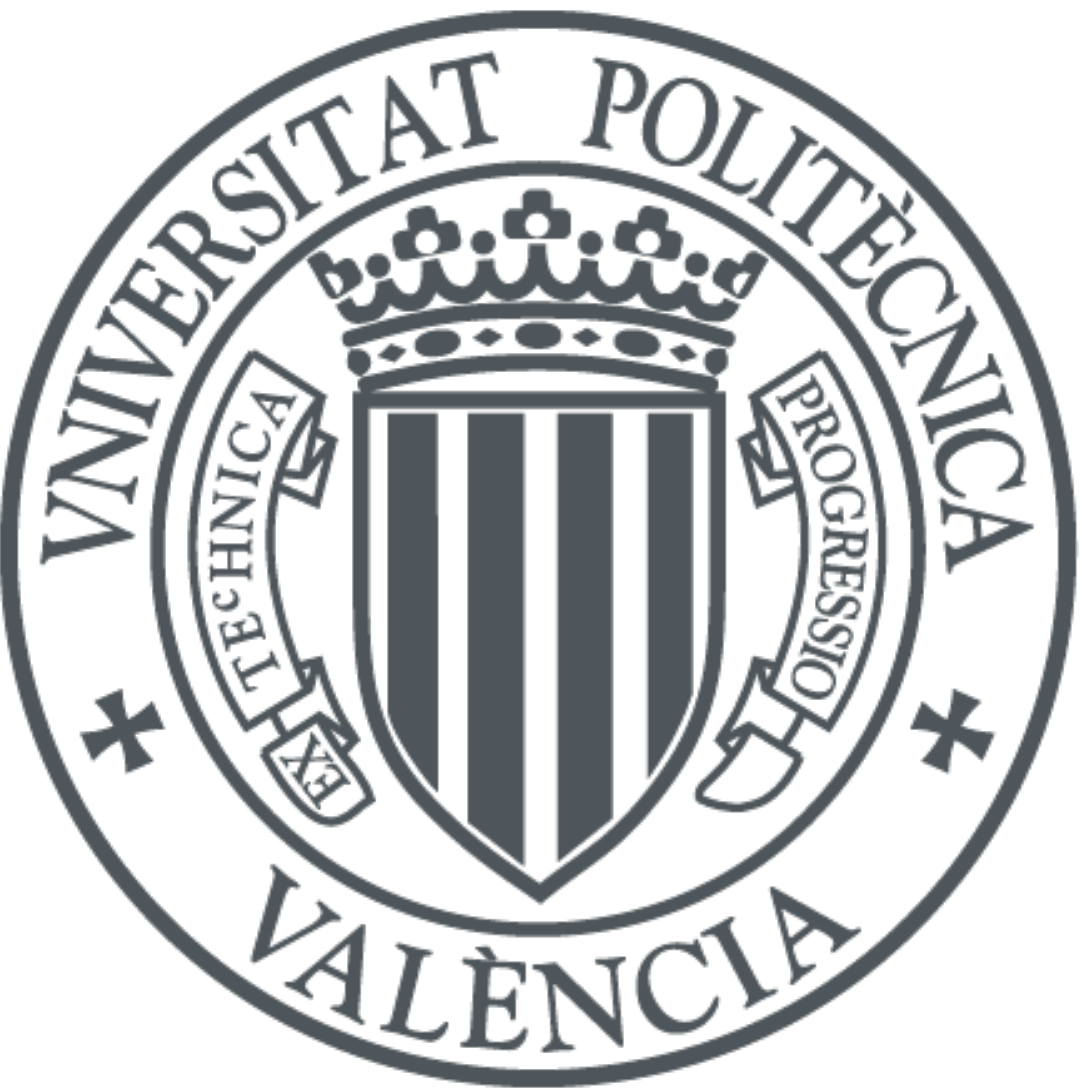

The final publication is available at

https://doi.org/10.1016/j.ijthermalsci.2018.10.043

Copyright Elsevier

Additional Information 


\section{NOTICE:}

this is the author's version of a work that was accepted for publication in International Journal of Thermal Sciences. Changes resulting from the publishing process, such as peer review, editing, corrections, structural formatting, and other quality control mechanisms may not be reflected in this document. Changes may have been made to this work since it was submitted for publication. A definitive version was subsequently published as [1]:

\section{References}

[1] J. Galindo, P. Piqueras, R. Navarro, D. Tarí, C. Meano, Validation and sensitivity analysis of an in-flow water condensation model for 3DCFD simulations of humid air streams mixing, International Journal of Ther-mal Sciences 136 (2019) 410 - 419. https://doi.org/10.1016/ j. ijthermalsci.2018.10.043. 


\title{
Validation and sensitivity analysis of an in-flow water condensation model for 3D-CFD simulations of humid air streams mixing
}

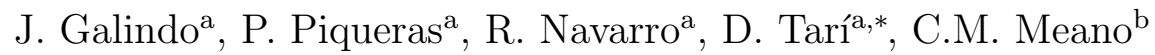 \\ ${ }^{a}$ CMT - Motores Térmicos, Universitat Politècnica de València \\ Camino de Vera, 46022 Valencia \\ ${ }^{b}$ GM Global Propulsion Systems-Torino Srl Corso Castelfidardo 36 - 10129 Torino (I)
}

\begin{abstract}
The mixing of gaseous streams at different humidity and temperature conditions may generate bulk condensation, which is a particular thermodynamic process that usually implies a great computational effort. A model that provides in-flow condensation predictions without heavily impacting on the simulation time becomes a potential tool for studying situations where the presence of water droplets is a problem. For instance, in a Long-Route Exhaust Gas Recirculation (LR-EGR) system, intake fresh air is mixed with humid and hot exhaust gases, generating water droplets that may impact on the turbo-compressor impeller and produce harmful erosion. Serrano et al. 11 developed a condensation submodel for such purpose. In this work, the 3D CFD methodology is analyzed by means of sensitivity studies on the numerical setup and intake throttle valve angle. Validation of the model is addressed by means of measurements in a fully instrumented continuous flow turbocharger test bench, obtaining quantitative and qualitative agreement. Particularly, a consistent correlation was found between predicted condensation rate and the impeller damage for seven LR-EGR configurations. Moreover, the T-joint geometry is noticed to have a great impact on condensation generation, thus showing the potential of such a 3D model for improving the LR-EGR design.
\end{abstract}

\footnotetext{
*Corresponding author. Tel.: +34 963877650

Email addresses: galindo@mot.upv.es (J. Galindo), pedpicab@mot.upv.es (P. Piqueras), ronagar1@mot.upv.es (R. Navarro), datade@mot.upv.es (D. Tarí), cesare.meano@gm.com (C.M. Meano)
} 
Keywords: Turbocharger, Computational Fluid Dynamics, Long-Route EGR, Condensation, Mixing, Model validation

\section{Introduction}

Tightening emissions standards require the developments of more sophisticated techniques for reducing pollutant emissions as well as increasing the efficiency of internal combustion engines [2, 3].

Exhaust gas recirculation (EGR) is a widely-used technique in engines since it provides a considerable reduction of the nitrogen oxides $\left(\mathrm{NO}_{x}\right)$ with a small impact on the specific fuel consumption [4, 5, 6]. It is usually employed in compression ignited engines, however its usage in spark ignited engines is beneficial as well [7, 8]. This technique has two variations, depending on where the exhaust gases are taken from and rerouted back. Short-route EGR (SR-EGR) connects both intake and exhaust manifolds. This approach allows fast transient response and high EGR rate [9]. However, cylinder-tocylinder EGR distribution may not be homogeneous [10], thus entailing an increase in $\mathrm{NO}_{x}$ and particulate matter emissions [11, and the compressor operating point moves closer to surge conditions due to the fresh mass flow reduction [4, 12].

Conversely, Long-Route EGR (LR-EGR) connects the exhaust line downstream the turbine and aftertreatment system with the intake line upstream the compressor. In this way, the compressor operates further from surge, the EGR cylinder distribution is homogeneous and the EGR gases are cleaner. Nevertheless, it provides a slower engine response due to the higher ducts volumes and lengths, but the main drawback of this solution is the possibility of water condensation in the EGR cooler or in the junction connecting the fresh air and EGR streams [13.

Focusing on the LR-EGR technique, one of the sources of condensation is the mixing of exhaust gases with fresh air coming from cold ambient, typically with temperatures below $5{ }^{\circ} \mathrm{C}$. Once condensation is produced, water droplets may reach the compressor wheel, which is commonly spinning at very high speed. The impact of the droplets against the leading edges of the compressor wheel causes a progressive erosion that worsens the performance of the compressor and may finally produce a fatal failure of the whole turbocharger [13]. Koka et al. [14] studied the reduction of the droplet damage on the wheel leading edges by covering the surface of the wheel with a protective coating. 
Serrano et al. [13] proposed a 0D "perfect mixing" model that calculates the amount of water that would condense following an isenthalpic process if the intake air and the EGR streams mixed perfectly, resulting in an homogeneous compressor inlet flow. This solution sets, by definition, a worst case scenario providing the maximum condensation rate due to the complete mixing. However, considering the importance of local effects on the mixing process and on the resulting condensation, it is interesting to address the problem using 3D-CFD simulations. For instance, Patel et al. [15] assessed the impact of several turbulence models on the condensation formation in low-pressure turbines and modified a k- $\omega$ SST model to improve the prediction accuracy. Sakowitz et al. [16] studied the mixing process in a T-junction using Large Eddy Simulation, varying the mass flow ratio between the two streams and analyzing the secondary flows. Different authors [17, 18] proposed models of water droplet appearance and growth due to the acceleration of the humid flow in a de Laval Nozzle.

The current work is addressed to validate a 3D-CFD model which predicts the vapor condensation that takes place when two streams at different psychrometric conditions (temperature and humidity) are mixed. As opposed to other physically-based approaches that deal with condensation by modeling the phase change process, droplet formation [18] or even droplet trajectories [19], the current model has a very low impact on the computational cost [1]. To the authors' knowledge, the proposed approach is a unique fast-solving tool that would allow performing multiple parametric studies or design optimization processes about LR-EGR condensation in a short time.

The condensation model proposed by Serrano et al. [1] is selected as a starting point. That model was developed and verified but lacks of a proper validation with experimental data. The difference between the verification and validation steps may not be clear, so it is briefly explained next. Verification consists in checking whether the actual implementation of the model is solving the problem as intended [20], and Serrano et al. [1] concluded that the condensation model solves the equations correctly and it is possible to estimate the condensation rate in a T-joint due to the mixing of streams at different psychrometric conditions. The validation process, which is conducted in the present work, determines if the model is faithfully representing the reality [20], commonly by comparing experimental data with results of the model using the same configuration and conditions [21, 22]. Before addressing the validation stage, sensitivity studies are conducted, assessing the influence of different setup and geometrical parameters to the stability of the 
model and the accuracy in terms of condensation production.

In Section 2, the condensation model is explained, focusing on the physical processes that are taking place. Afterwards, the experimental setup is described in Section 3. Next, the numerical model and the sensitivity study are presented in Section 4 and finally, the validation process is developed in Section 5. The conclusions obtained are exposed in Section 6.

\section{Condensation model}

The mixing of humid air streams is addressed in this work modeling the transport of both dry air and water vapor species with STAR-CCM $+{ }^{\circledR}[23]$. Constant values are considered for the thermal properties of each component, performing a mass-weighted average to obtain mixture properties. A subroutine has been implemented in STAR-CCM+ ${ }^{\circledR}[1]$ to model condensation of liquid water in the bulk flow. This model was verified by Serrano et al. [1] and is due for validation in this work.

The condensation model estimates the quantity of condensates that a given cell of the simulation geometry may produce in order to reach an equilibrium state at saturated conditions, following an isenthalpic process. The estimation of the vapor that condenses is calculated with the psychrometric variables of the gas, i.e. temperature, pressure and specific humidity. Then, the model interacts with the numerical solver through the transport equation source terms, replicating the actual condensation process. The simplifications and hypotheses that were assumed for the model implementation are:

- Instantaneous condensation: since low velocities control LR-EGR mixing, it is acceptable to assume the condensation to occur instantaneously in time and space. Conversely, this consideration is needed to be taken into account in cases with very high velocities, such as in steam turbines or rocket engines [17, 15, 24].

- Condensed liquid water is not modeled. Liquid water mass fraction is below $0.5 \%$ of total humid air, even with high condensing boundary conditions. Therefore, the impact of this simplification on the conservation of the transport variables is negligible.

Taking into account the hypotheses and simplifications exposed above, the implementation of the condensation model is addressed by introducing 
custom source terms into the transport equations of the CFD calculation. These equations can be obtained considering the appropriate term of the general equation in discrete form with each transport term. These terms are mass fraction $(Y)$ and diffusion coefficient $(D)$ for the species equation, velocity $\left(u_{i}\right)$ and kinematic viscosity $(\nu)$ for the momentum equation and enthalpy $(h)$ and thermal diffusivity $(\alpha)$ for the energy equation. Equation (1) and Table 1 summarize the transport equation system.

$$
\frac{\partial(\rho \varphi)}{\partial t}+\nabla(\rho \varphi \vec{u})=\nabla\left(\rho \Gamma_{\varphi} \nabla(\varphi)\right)+S_{\varphi}
$$

\begin{tabular}{c|c|c|c} 
Equation & $\boldsymbol{\varphi}$ & $\boldsymbol{\Gamma}_{\boldsymbol{\varphi}}$ & $\boldsymbol{S}_{\boldsymbol{\varphi}}$ \\
\hline Mass & 1 & - & $S_{v a p}$ \\
Species & $Y$ & $D$ & $S_{v a p}$ \\
Momentum & $\vec{u}$ & $\nu$ & $-\nabla p+\vec{f}_{m}+\vec{f}_{v}+\vec{S}_{\text {mom. }}$ \\
Energy & $h$ & $\alpha$ & $-D p / D t+f_{t}+f_{\nu}+S_{\text {ener. }}$
\end{tabular}

Table 1: Transport equations.

Condensation occurs when the relative humidity is above saturated conditions, i.e. $R H>100 \%$. This condition triggers the calculation of the source terms that are introduced in the transport equations. A representation example of the process is shown in Fig. 1. Point 1 would be the starting point when, in a given cell, hot humid exhaust gas is mixed with dry cold ambient flow and the resultant product is at over-saturated conditions. Then, the objective is to find the point on the saturated curve that has the same enthalpy [25, 26]. The calculation of this point is implicit, being required the use of an iterative process. Point 2 is calculated at iso-specific humidity at saturated conditions and point 3 is calculated isothermally at saturated conditions. Equation (2) shows that with the enthalpies of points 1,2 and 3 the weighted specific humidity of point (f) is obtained. This process can be repeated $n$ times to find an accurate value of this parameter, being the condensation produced in a single CFD solver iteration and in a single cell. Serrano et al. [1] concluded, during the verification process of the model, that it was less computationally demanding to perform a single iteration of the condensation calculation, leaving the convergence of the solution to the downstream cells and increase the mesh definition to reduce this diffusive effect. 


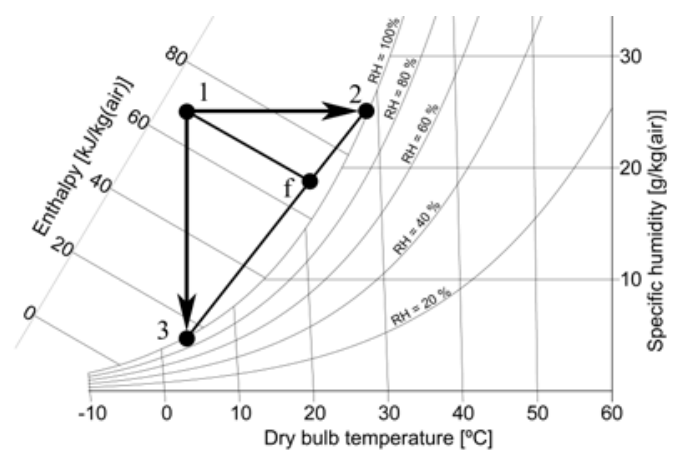

Figure 1: Psychrometric diagram with a representation of the condensation solving process.

$$
w_{f}=\frac{w_{2}-w_{3}}{h_{2}-h_{3}}\left(h_{1}-h_{3}\right)+w_{3}
$$

The vapor source term can be calculated considering the initial specific humidity (point 1), the specific humidity obtained from the previous interpolation (point $\mathrm{f}$ ), the dry air mass fraction and a characteristic condensation time (residence time of the flow at a given cell), following equation (3).

$$
S_{\mathrm{vap}}=\frac{\rho Y_{\mathrm{air}}\left(w_{f}-w_{1}\right)}{\Delta \mathrm{t}}
$$

The calculation of the momentum source is straightforward, being it defined as the vapor source times the velocity vector, as shown in equation (4).

$$
\vec{S}_{\text {mom. }}=S_{\text {vap }} \vec{u}
$$

Finally, the energy source takes into account the latent heat released to the flow by the condensed water and the sensible heat of the vapor source that is removed with its associate mass. It is showed in Eq. 5 .

$$
S_{\text {ener. }}=-S_{\text {vap }}\left(L-c_{p_{v}} T\right)
$$

\section{Experimental setup}

\subsection{Facility}

The facility used in this work is based on the turbocharger test bench described by Luján et al. 27] and Tancrez et al. 28]. For this work, the gas 
stand has been upgraded and is capable to reproduce hot, humid air as EGR. In Figure 2 it is depicted a diagram of the enhanced rig configuration. In first place, air is compressed in a screw compressor and heated up to around $500{ }^{\circ} \mathrm{C}$. Part of this flow is expanded in the turbine, driving power to the compressor. The rest of the hot compressed air is splitted in a three-way valve and conditioned to simulate the LR-EGR flow. For doing so, a certain mass flow rate of water is injected within this flow. The water evaporates due to the high temperature of the air and before being re-introduced upstream the compressor, its temperature is reduced in the LR-EGR cooler to a desired value. Separately, air is cooled and dried in a climatic chamber and connected to the compressor intake line. This air simulates cold ambient conditions. As aforementioned, the LR-EGR flow is blown upstream the compressor through a $\mathrm{T}$-joint valve which consists in a simple perpendicular intersection of circular ducts, with flaps to control the mass flow rates. The intake flap was fixed at a high angle.

The instrumentation used allows a continuous measurements of the variables needed to control the test rig and characterize the region of interest upstream the compressor. The intake air mass flow rate is measured with an engine flow meter mounted in the air box filter. The mass flow rate downstream the compressor is measured using a Vortex flow meter, since the high humidity of the gas made it impossible to use a conventional hot wire/plate flow meter. With those parameters it is possible to calculate the LR-EGR mass flow rate by difference. An inductive PICOTURN compressor speed sensor is mounted in the compressor wheel to measure its spinning rate. A transparent duct is placed at the LR-EGR cooler outlet to assure the absence of water droplets coming from it. Piezoresistive pressure sensors are mounted along the different ducts of the rig. Their specifications are noted in the Table 2. For the temperature sensors, K-type thermocouples are used, the specifications of these sensors are listed in the Table 3.

\begin{tabular}{|l|r|}
\hline Type & Piezoresistive KISTLER RAG25A52BV1H \\
\hline Range & 0 to 5 bar \& 0 to 2 bar (comp. inlet) \\
\hline Output signal & $0 \ldots 10 \mathrm{~V}$ \\
\hline
\end{tabular}

Table 2: Pressure sensors specifications. 


\begin{tabular}{|l|r|}
\hline Type & Watlow thermocouple K-type \\
\hline Range & -200 to $1270{ }^{\circ} \mathrm{C}$ \\
\hline Output signal & $41 \mu \mathrm{V} /{ }^{\circ} \mathrm{C}$ \\
\hline
\end{tabular}

Table 3: Thermocouples specifications.

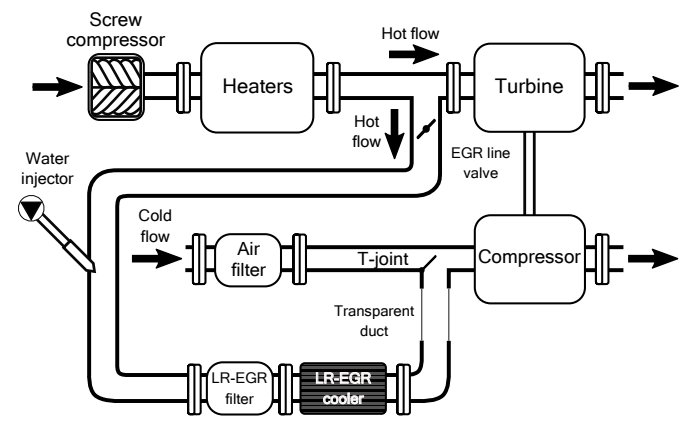

Figure 2: Diagram of the continuous flow turbocharer test rig with water injection for humid EGR gas replication.

\subsection{Description of durability test}

Including the aforementioned T-joint configuration, which will be used as a baseline, seven durability tests of 50 hours are performed with different geometries and flaps in order to assess a potential compressor wheel damage and thus, provide data for validation. For this, a reasonable example of an engine operating point is replicated in terms of compressor mass flow, EGR rate and specific humidity of the exhaust gases that would be generated during the combustion. Fresh dry air is taken from a climatic chamber at temperatures below $0{ }^{\circ} \mathrm{C}$. The EGR rate is fixed to be $15 \%$, a common value for the selected operating point.

For the characterization of the problem that is addressed in this work, the duct between the LR-EGR discharge and the compressor inlet is instrumented with a thermocouple that can be moved to measure different points contained in a cross-section plane in the mixing region, $55 \mathrm{~mm}$ downstream of the LR-EGR discharge duct axis. These measurement points are distributed following a cross pattern including one in the center, resulting in a total of 5 points. The temperature measurement at each point is performed during 10 hours.

The pressure drop introduced by the T-joint system is also measured 
placing a piezoresistive pressure sensor in the air box filter and another in the compressor inlet. The pressure drop will be compared with the pressure drop generated by the same T-joint when the intake flap is removed.

Finally, at the end of the 50 testing hours, the T-joint is removed from the compressor inlet and a picture of the state of the compressor wheel is taken, evaluating if there is erosion or damage on the inducer.

\section{Numerical configuration}

In this part, the influence of different parameters of the 3D-CFD simulation setup on the performance of the condensation model implemented within the software is assessed. In the end, the robustness of the condensation model to changes of these parameters is tested. In addition, an optimized setup is selected for the rest of the validation process.

\subsection{Geometry and baseline setup}

The modeled geometry represents the actual T-joint valve used in the experimental part of this work. This kind of T-joint has been widely used previously to study the mixing process of two streams in order to assess the accuracy of different turbulent approaches [29].

A preliminary study was conducted to determine the length of the ducts required to define the numerical domain. It was found that three intake diameters upstream the intake flap and two EGR duct diameters upstream the EGR flap are required so that the boundary conditions do not affect the domain of interest, allowing a proper development of the flow before reaching the respective flap. In addition, the results presented a low sensitivity to the value of turbulence intensity imposed at the boundary conditions, and hence a standard value of $4 \%$ is used. Finally, five intake diameters are extruded downstream the intake flap in order to be able to observe a fair length of the mixing process between both flows. A detailed view of the geometry is showed in Fig. 3.

An initial numerical setup is required to be used as a baseline for the sensitivity analyses. The segregated solver of STAR-CCM+ ${ }^{\circledR}[23$ ] is considered through this work. The coupled solver was not considered since Mach number in this application does not exceed values of 0.3 . The domain is composed by a mesh of $0.5 \mathrm{M}$ polyhedral cells with a base size of $1.7 \mathrm{~mm}$. For a better resolving of the flow near the walls, a prism layer configuration is set, composed by 8 layers with a growth rate of 1.3 and a total thickness 


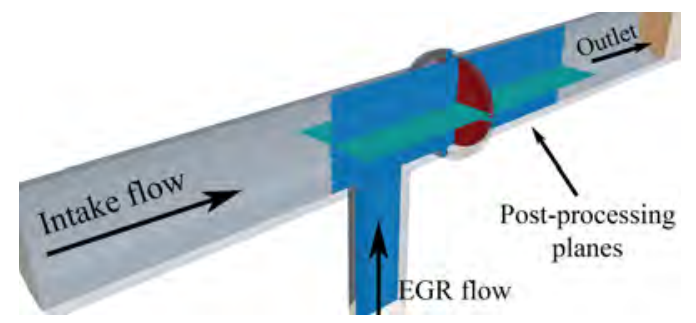

Figure 3: Numerical domain and post-processing planes of the selected LR-EGR geometry.

of $1.275 \mathrm{~mm}$. This provides $\mathrm{y}^{+}$values of unity in the wall cells, which allows viscous sublayer resolution. A representative section plane of the mesh is depicted in Fig. 4. A Reynolds Averaged Navier-Stokes approach for the turbulence solver is chosen, closing the equation system with the Standard $k-\epsilon$ submodel [30, 31]. Costa et al. [32] used this model to simulate mixing processes as well. Both inlets are configured with a mass flow inlet boundary condition, whereas static pressure is set at the outlet of the T-joint. These boundary values are obtained averaging their correspondent magnitude of the experimental test. Steady-state calculations are considered, thus sparing the time discretization. Heat transfer with the surroundings is neglected, so that the walls are regarded as adiabatic. The centrifugal compressor existing downstream the T-joint is omitted in the simulations for the sake of computational cost, since Galindo et al. [33] showed that the impact of including the compressor on the condensation prediction is below $4 \%$.

\subsection{Mesh independence}

The sensitivity study starts with the assessment of the mesh independence. For this, the aforementioned reference case is considered and two additional meshes are proposed. Since the reference one has $0.5 \mathrm{M}$ cells, a coarse mesh of $0.1 \mathrm{M}$ cells and a fine mesh of $2 \mathrm{M}$ are generated. The base size of the additional meshes are 3.5 and $0.9 \mathrm{~mm}$ for the coarse and fine mesh respectively. The other cell-related parameters are scaled with the base size, such as the prism layer thickness. Starting from the coarse mesh, the grid refinement for obtaining a fine mesh is therefore substantial and performed in a systematic way, as suggested by Ferziger and Perić [34. A detailed picture of a cross-section of the generated meshes can be seen in Figure 4.

After iterating the solutions until achieving convergence, imbalances of the transport equation are used for the comparison. Air and water mass 
imbalances are calculated using Eqs. 6 and 7 and for the energy imbalance, Eq. 8 is used.

$$
\begin{aligned}
& \delta_{\text {air }}(\% 0)=\frac{\dot{m}_{\text {air }}^{\text {in }}+\dot{m}_{\text {air }}^{\mathrm{EGR}}-\dot{m}_{\text {air }}^{\text {out }}}{\dot{m}_{\text {air }}^{\text {in }}+\dot{m}_{\text {air }}^{\text {EGR }}} \cdot 1000 \\
& \delta_{\text {water }}(\% \text { o })=\frac{\dot{m}_{\text {vap }}^{\text {in }}+\dot{m}_{\text {vap }}^{\text {EGR }}-\left(\dot{m}_{\text {vap }}^{\text {out }}+\dot{m}_{\text {water }}^{\text {out }}\right)}{\dot{m}_{\text {vap }}^{\text {in }}+\dot{m}_{\text {vap }}^{\text {EGR }}} \cdot 1000 \\
& \delta_{\text {ener. }}(\% \text { o })=\frac{h^{\text {in }} \dot{m}^{\text {in }}+h^{\mathrm{EGR}} \dot{m}^{\mathrm{EGR}}-h^{\text {out }} \dot{m}^{\text {out }}+\int_{V} S_{\text {ener. }} \mathrm{d} V}{h^{\text {in }} \dot{m}^{\text {in }}+h^{\text {EGR }} \dot{m}^{\text {EGR }}} \cdot 1000
\end{aligned}
$$

The condensation rate is normalized with the dry air mass flow rate, showed in Eq. 9.

$$
\hat{\dot{m}}_{\text {water }}\left(g_{\text {water }} / k g_{\text {air }}\right)=\frac{\dot{m}_{\text {water }}^{\text {out }}}{\dot{m}_{\text {air }}^{\text {in }}+\dot{m}_{\text {air }}^{\text {EGR }}} \cdot 1000
$$

Finally, the relative difference between each case and the one with the finest discretization is calculated using Eq. 10 .

$$
\epsilon_{\hat{\dot{m}}_{\text {water }}}(\% 0)=\frac{\hat{\dot{m}}_{\text {water }}-\hat{\dot{m}}_{\text {water,fine }}}{\hat{\dot{m}}_{\text {water,fine }}} \cdot 1000
$$

A summary of the results obtained in this study is shown in Table 4 .

\begin{tabular}{|l|c|c|c|}
\hline Millions of cells (-) & $\mathbf{0 . 1}$ & $\mathbf{0 . 5}$ (ref) & $\mathbf{2}$ \\
\hline $\boldsymbol{\delta}_{\text {air }}(\boldsymbol{\% o})$ & 0.74 & 0.01 & 0.05 \\
\hline $\boldsymbol{\delta}_{\text {water }}(\%)$ & 0.87 & 0.18 & 0.20 \\
\hline $\boldsymbol{\delta}_{\text {ener. }}(\%)$ & 2.20 & 0.99 & 1.06 \\
\hline$\hat{\boldsymbol{m}}_{\text {water }}\left(\boldsymbol{g}_{\text {water }} /\right.$ kg $\left._{\text {air }}\right)$ & 1.79 & 1.80 & 1.80 \\
\hline $\boldsymbol{\epsilon}_{\hat{\boldsymbol{m}}_{\text {water }}}(\%)$ & 19.2 & 3.1 & - \\
\hline
\end{tabular}

Table 4: Imbalances and condensation rate results of mesh independence study.

Considering the imbalances, the discretization error of the coarse mesh is significantly larger than that obtained by the other meshes, even though all of them are below a tight threshold. Table 4 also shows the ultimate result of the simulation, namely the condensation rate. In this way, relative error 
of the condensation rate predicted by the reference mesh against the finest one is only $3 \%$, whereas the coarsest mesh increases this error by a order of magnitude.

As Table 4 only provides quantitative global results of the simulations, in Figure 4 it is depicted the temperature distribution in the cross-section planes of the main duct (see Fig. 3), downstream of the intake flap. It can be observed the similarities between the fine mesh and the reference one, whereas the coarse mesh presents clear differences in the temperature distribution, implying a poorly accurate solution. It is obvious that the fine grid should present a lower discretization error, but it is not worth using it due to the greater computational effort it requires. Hence, the base size of the reference 0.5 million cell mesh is kept since it presents the best trade-off.

\subsection{Time discretization}

The next step consists in studying the influence of the time discretization on the simulation results. The reference case is set as steady, thus a transient discretization is going to be analyzed by imposing different time steps. To have an order of magnitude of the shedding frequency of the vortices generated downstream the intake flap, the Strouhal dimensionless number is considered (Eq. 11), which links this frequency with the flow rate parameters.

$$
S t=\frac{f r l}{U}
$$

To calculate the frequency, the characteristic Strouhal number of the problem ought to be estimated in first place. With the study performed by Chen and Fang [35] about the Strouhal numbers of flat inclined flaps in free streams, it is obtained a Strouhal of 0.2 for the current case. Using the definition of the Strouhal number (Eq. 11), the minor axis of the projection of the flap on a cross section as a characteristic length and the velocity of the flow at a common operating condition, a frequency can be calculated. The shedding frequency of vortices is around $120 \mathrm{~Hz}$, hence imposing a resolution of forty time steps for each oscillation, the time step should be around $2 \cdot 10^{-4} \mathrm{~s}$. From this value, two additional cases are proposed with a quarter and a tenth of that time step $\left(5 \cdot 10^{-5} s, 2 \cdot 10^{-5} s\right)$.

Following the same process as in Section 4.2, in Table 5 the imbalance results and the condensation rate at the outlet of each case are summarized, considering time-averaged results. 


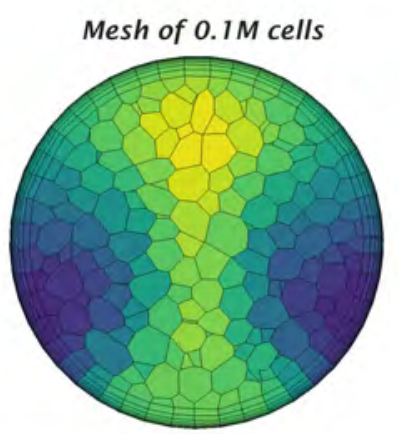

Mesh of $0.5 \mathrm{M}$ cells

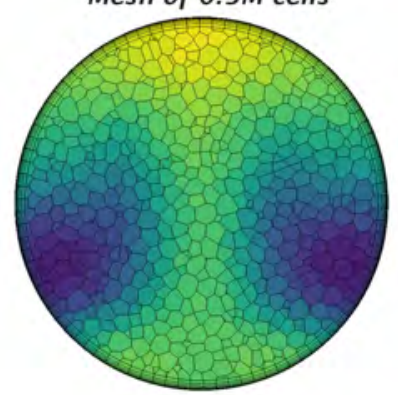

Mesh of $2 M$ cells

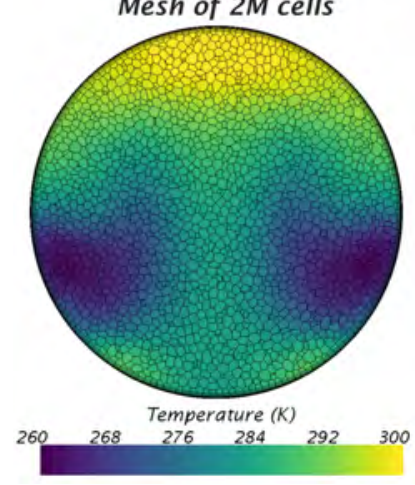

Figure 4: Temperature field in the cross-section $55 \mathrm{~mm}$ downstream the EGR axis.

Reduced imbalances are found for all these cases. Compared with the steady reference case, the transient cases behave slightly worse in terms of imbalances. The error in condensation rate of the steady solution compared with the smallest time step transient calculation $\left(\Delta t=2 \cdot 10^{-5} \mathrm{~s}\right)$ is around 1\% (see Table 5). The increase of computational effort to conduct transient simulations is not worth the improvement in precision. The steady-state solver presents little error since the flow solution is quite stable. For other 


\begin{tabular}{|c|c|c|c|c|}
\hline Time step (ms) & Steady (ref) & 0.2 & 0.05 & 0.02 \\
\hline$\delta_{\text {air }}(\%)$ & 0.01 & 0.09 & 0.21 & 0.37 \\
\hline$\delta_{\text {water }}(\%)$ & 0.18 & 2.55 & 0.86 & 1.28 \\
\hline$\delta_{\text {ener. }}(\%)$ & 0.99 & 1.43 & 1.58 & 1.53 \\
\hline$\hat{\dot{m}}_{\text {water }}\left(g_{\text {water }} / k_{g_{a i r}}\right)$ & 1.80 & 1.80 & 1.80 & 1.79 \\
\hline$\epsilon_{\hat{\dot{\boldsymbol{m}}}_{\text {water }}}(\% 0)$ & 10.1 & 8.6 & 2.2 & - \\
\hline
\end{tabular}

Table 5: Imbalances and condensation rate results of time step sensitivity study.

configurations, consisting in different geometries or operating conditions, unsteady phenomena such as flow detachment may appear. In such cases, the residuals would present significant oscillations when attempted to be simulated with a steady solver. A transient solver should be rather used, conducting a time step sensitivity analysis such as the one presented in Table 5 .

\subsection{Turbulence approach}

Regarding the turbulence modeling, no scale-resolving methods are assessed in this work due to the substantial increase of computational effort that they would require. As aforementioned, the RANS Standard $k-\epsilon$ closure model is used for the reference case, since it is widely used in flow mixing problems. In addition to this model, another RANS closure model is tested, the $k-\omega$ SST model [36]. The shear stress transport (SST) equations combine the use of the $k-\omega$ model in the inner parts of the boundary layer and the $k-\epsilon$ model in the free-stream. This model claims to provide a better solution to adverse pressure gradient conditions [36], such as those found downstream of the flaps.

In the same manner as in the previous comparisons, in Table 6 are summarized the results of the imbalances and condensation rates of the different turbulence approaches used.

Low errors in the imbalances are found for both turbulent approaches. The slightly higher condensation rate can be due to local flow resolving differences inherent to the turbulence model. Nevertheless, the difference in condensation rate is below $4 \%$, so the impact of the turbulence approach is not excessively significant. The election of the RANS turbulent model depends thus on external parameters that are not related with the condensation model but with the flow problem. In this case it is chosen to solve 


\begin{tabular}{|l|c|c|}
\hline Turbulence model & $k-\epsilon($ ref $)$ & $k-\omega$ SST \\
\hline $\boldsymbol{\delta}_{\text {air }}(\%)$ & 0.01 & 0.04 \\
\hline $\boldsymbol{\delta}_{\text {water }}(\%)$ & 0.18 & 0.04 \\
\hline $\boldsymbol{\delta}_{\text {ener. }}(\%)$ & 0.99 & 1.55 \\
\hline$\hat{\boldsymbol{m}}_{\text {water }}\left(\boldsymbol{g}_{\text {water }} / \mathbf{k g}_{\text {air }}\right)$ & 1.80 & 1.88 \\
\hline
\end{tabular}

Table 6: Imbalances and condensation rate of different turbulence approaches.

future simulations with the $k-\omega$ model since it presents a wider usage in automotive gas exchange 3D-CFD simulations in the latest years.

\subsection{Flap angle}

During the experimental tests it was observed an important sensitivity of the flap angle in the temperature distribution downstream the mixing region. This change in the temperature profile is caused by a modification of the flow structure within the mixing region, since each stream has a different temperature. Changes in the flow structure imply different mixing behaviors and hence, different condensation rates. So it is important to estimate the impact of this sensitivity with the simulations.

A swept in flap angle is defined varying around the tested angle $\left(74^{\circ}\right)$ from $65^{\circ}$ to $83^{\circ}$ by steps of $3^{\circ}$, resulting in a total of 7 cases. The valve is wide open at $0^{\circ}$ and totally closed at $90^{\circ}$. For the rest of the setup, the baseline configuration is used with $k-\omega \mathrm{SST}$ as turbulence submodel. So in this case, the results that are compared are concerning the flow structure (temperature distribution and condensation rate) and pressure drop.

The pressure drop is calculated subtracting the pressure difference of the intake inlet and a cross section plane downstream the mixing region of a flap-less configuration case to the pressure difference of a case with a certain flap angle. The results are showed in Table 7.

\begin{tabular}{|c|c|c|c|c|c|c|c|}
\hline Flap angle & $\mathbf{6 5}^{\circ}$ & $\mathbf{6 8}^{\circ}$ & $\mathbf{7 1}^{\circ}$ & $\mathbf{7 4}^{\circ}$ & $\mathbf{7 7}^{\circ}$ & $\mathbf{8 0}^{\circ}$ & $\mathbf{8 3}^{\circ}$ \\
\hline $\boldsymbol{\Delta} \mathbf{p}(\mathbf{m b a r})$ & 39.2 & 41.7 & 45.1 & 47.7 & 50.8 & 54.4 & 57.6 \\
\hline
\end{tabular}

Table 7: CFD prediction of pressure drop generated by the flap at different angles.

Within this range, the pressure drop behaves linearly with the flap angle. A small modification of the flap angle provides a significant change in pressure 
drop since the valve is operating not far from its closed position.

Concerning the flow structures, a good indicator is the temperature distribution in a cross section plane within the mixing region. For the next comparison, contour planes are made coinciding with the position of the thermocouple in the tests, as will be used in the validation afterwards. In Figure 5 it is depicted the temperature contours at that said section position for three angle positions, namely $65^{\circ}, 74^{\circ}$ (reference case) and $83^{\circ}$.

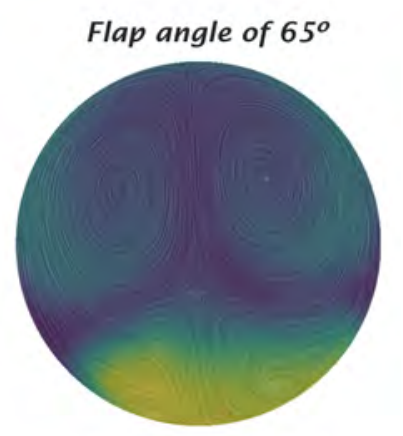

Flap angle of $74^{\circ}$

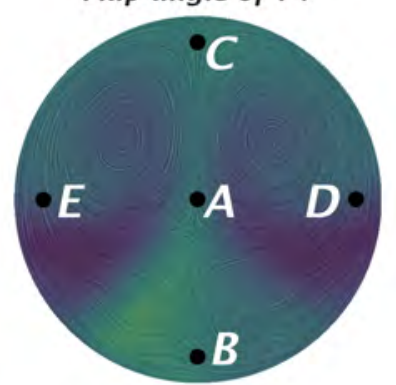

Flap angle of $83^{\circ}$

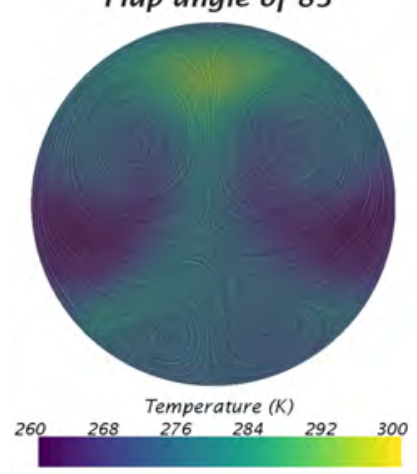

Figure 5: Temperature field on a cross section $55 \mathrm{~mm}$ downstream the intake flap. 
From the different temperature distributions, it can be concluded, as stated previously, that the flow structures are very permeable to the flap angle. In this case, the EGR flow reaches the top part of the T-joint duct with higher flap angles. The closest position of the flap prevents the intake flow of transferring momentum to the EGR flow (hotter), implying a smaller deflection. The absence of deflection also generates a recirculating region right upstream the EGR flow discharge.

Finally, to conclude the sensitivity study, the impact of the flap angle in the condensate production is conducted. In Figure 6 the evolution of the condensation rate of all the flap angle positions is displayed. In addition, the normalized condensation rate of the $0 \mathrm{D}$ perfect mixing solution [13] is showed, and as aforementioned, this sets a worst case scenario that acts as an upper bound. Theoretically, if given enough duct distance, both streams would completely mix and the condensation rate would achieve the solution of the 0D model.

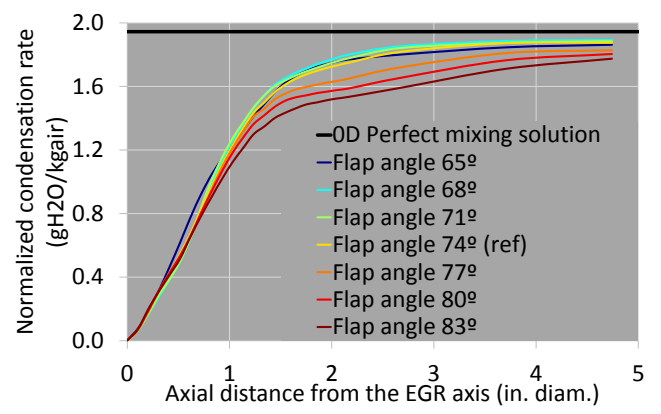

Figure 6: Normalized condensation rate results of flap angle study compared with perfect mixing solution.

In spite of the differences in the flow structures found in the previous studies, their repercussion on the normalized condensation rate may not be such clear. In this case, the mixing processes generated by flap angles between $65^{\circ}$ and $74^{\circ}$ lead to similar normalized condensation rates. However, for higher flap angles a slight reduction of normalized condensation rate is observed. It can be inferred that a particular normalized condensation rate is associated to each flow structure, and no linear behavior may be found between geometrical parameters and the normalized condensation rate produced. Moreover, the flow structures are sensitive to the geometry, so special attention may be paid when trying to reproduce actual geometries. 


\section{Validation results}

\subsection{Pressure drop and temperature measurements}

From the sensitivity study it is obtained the base configuration which is used for the validation. As aforementioned, it is selected the reference mesh in steady state conditions with a $k-\omega$ SST turbulence approach. The boundary conditions imposed are obtained averaging their value during the experimental test. The validation of the model using experimental data is first addressed comparing the pressure drop of the T-joint and the temperature distribution in the section plane introduced previously. In addition, a qualitative comparison between the erosion observed in the compressor wheel of seven different T-joint configurations, after 50-hour durability tests, and their modeled condensation rate in the inducer plane is performed in Section 5.2, completing the validation assessment.

First, the error in pressure drop is evaluated. The experimental measurements carried out with the test rig described in Section 3.1 employed an intake throttle valve at a position of $74^{\circ}$. However, as pointed out by Galindo et al. [37], it is difficult to guarantee that the actual flap position when running the experiment is not slightly deviated from the intended $74^{\circ}$. Therefore, the sensitivity of the CFD predictions to the flap angle is assessed with the following definition:

$$
\epsilon_{\Delta p, \beta}(\%)=\frac{\Delta p_{C F D_{\beta}}-\Delta p_{\exp _{74}}}{\Delta p_{\exp _{74}}} \cdot 100
$$

Table 8 presents the relative error of CFD prediction at a certain flap angle compared to the experimental measurement at $74^{\circ}$. As aforementioned, these values are obtained subtracting the pressure drop of a flap-less configuration to each case, for both modeled and tested configurations.

\begin{tabular}{|l|c|c|c|c|c|c|c|}
\hline Flap angle & $\mathbf{6 5}^{\circ}$ & $\mathbf{6 8}^{\circ}$ & $\mathbf{7 1}^{\circ}$ & $\mathbf{7 4}^{\circ}$ & $\mathbf{7 7}^{\circ}$ & $\mathbf{8 0}^{\circ}$ & $\mathbf{8 3}^{\circ}$ \\
\hline$\epsilon_{\boldsymbol{\Delta} \mathbf{p}, \beta}(\%)$ & -23 & -19 & -12 & -7 & -1 & 6 & 12 \\
\hline
\end{tabular}

Table 8: Relative error between CFD predictions of pressure drop generated with different flap angles and experimental measurement at $74^{\circ}$.

Results displayed in Table 8 show that CFD simulations with flap angles between $71^{\circ}$ and $83^{\circ}$ predict a pressure drop within $\pm 15 \%$ of error when compared to that of the experiment with an intended flap angle of $74^{\circ}$. Note 
that the model errors and uncertainties [20] and experimental flap angle and pressure sensors uncertainties are affecting to $\epsilon_{\Delta p, \beta}$ shown in Table 8 .

Next, the temperature measurements at the compressor inlet are compared with the results of the simulation. Each temperature value has been obtained averaging during 10 hours of testing. In Figure 5 it is highlighted the zones at the cross-section where the thermocouples A-E were actually placed. In Table 9 the error between the simulations of the different flap angles and measurement at $74^{\circ}$ is shown, calculated using the following expression for each location $j$ of the probe:

$$
\Delta T_{j, \beta}(K)=T_{C F D_{j, \beta}}-T_{\exp _{j, 74}}
$$

A root mean square error (RMSE) is calculated for each CFD flap angle position using Eq. 14 in order to include all the probes.

$$
R M S E_{T, \beta}(\%)=\sqrt{\sum_{j=A}^{E}\left(\frac{\Delta T_{j, \beta}}{T_{\exp _{j, 74^{\circ}}}} \cdot 100\right)^{2}}
$$

\begin{tabular}{|c|c|c|c|c|c|c|c|c|}
\hline & Test & \multicolumn{7}{|c|}{$\Delta T_{j, \beta}(K)$} \\
\hline Probe & $\mathbf{T}(\mathbf{K})$ & $\mathbf{6 5}^{\circ}$ & $\mathbf{6 8}^{\circ}$ & $\mathbf{7 1}^{\circ}$ & $\mathbf{7 4}^{\circ}$ & $\mathbf{7 7}^{\circ}$ & $\mathbf{8 0}^{\circ}$ & $\mathbf{8 3}^{\circ}$ \\
\hline A & 296 & -9 & $\mathbf{0}$ & -1 & 5 & 5 & 6 & 6 \\
\hline B & 296 & 8 & 3 & 4 & $\mathbf{1}$ & $-\mathbf{1}$ & -3 & -4 \\
\hline C & 272 & $\mathbf{0}$ & 6 & 6 & 9 & 12 & 14 & 15 \\
\hline D & 268 & 5 & $\mathbf{0}$ & $\mathbf{0}$ & $\mathbf{0}$ & -1 & -2 & -2 \\
\hline E & 271 & 1 & $\mathbf{0}$ & $\mathbf{0}$ & -2 & -2 & -3 & -3 \\
\hline \multicolumn{2}{|r|}{ RMSE $_{T} \mathbf{( \% )}$} & 13 & 6.8 & 7.3 & 10.8 & 13.3 & 15.9 & 17 \\
\hline
\end{tabular}

Table 9: Errors between CFD prediction of temperature with different flap angles and experimental measurements at $74^{\circ}$, for different probe locations.

Table 9 shows that CFD simulations with flap angles between $65^{\circ}$ and $77^{\circ}$ obtain a RMSE below $15 \%$. Therefore, the common range of CFD flap angles $\beta$ providing $\epsilon_{\Delta p, \beta}$ and $R M S E_{T, \beta}$ within $15 \%$ is $71^{\circ}-77^{\circ}$, centered in the intended $74^{\circ}$ valve position for the experiments. In this way, the flap angle in the test actually was located as expected, but the great sensitivity of the results to the valve angle needs to be carefully addressed when simulating this LR-EGR systems. 


\subsection{Durability tests}

Finally, seven durability tests are performed combining operating points with different inlet conditions and different $\mathrm{T}$-joint configurations. In Table 10 the conditions of EGR temperature and EGR specific humidity are summarized. These values have been chosen as reasonable examples of operating conditions of a compression ignited engine with a LR-EGR system. All the cases were performed with a EGR rate of $15 \%$ and very cold intake temperature (below $0^{\circ} \mathrm{C}$ ). These geometries with their corresponding boundary conditions were simulated, and the condensation rates predicted at the outlet of the T-joint are compared with the erosion detected on the leading edges of the compressor wheel after the 50 hours of durability testing. In Table 10 this comparison is summarized, relating the normalized condensation rate predicted by CFD with the experimentally-observed presence of erosion. The condensation rate is normalized with the case that produced a slight erosion on the impeller.

\begin{tabular}{|c|c|c|c|c|}
\hline Geom. & $\mathbf{T}_{\text {EGR }}$ & $\mathbf{w}_{\text {EGR }}$ & $\begin{array}{c}\text { CFD } \\
\text { norm. } \\
\text { cond. } \\
\text { rate }\end{array}$ & $\begin{array}{c}\text { Exp. } \\
\text { obs. } \\
\text { erosion }\end{array}$ \\
\hline$(-)$ & $\left({ }^{\circ} \mathrm{C}\right)$ & $(\mathrm{g} / \mathrm{kg})$ & $(-)$ & $(-)$ \\
\hline i & 60 & 70 & 1.48 & Yes \\
\hline ii & 60 & 70 & 1.41 & Yes \\
\hline iii & 90 & 60 & 1.11 & Yes \\
\hline i & 90 & 50 & 1 & Slight \\
\hline iv & 90 & 70 & 0.98 & No \\
\hline v & 60 & 70 & 0.78 & No \\
\hline vi & 90 & 70 & 0.58 & No \\
\hline
\end{tabular}

Table 10: Comparison between the erosion observed experimentally on the leading edges after 50 hours of durability test and the CFD prediction of condensation rate of seven different T-joint valve configurations.

Three of the configurations tested produced a noticeable erosion on the leading edges of the compressor wheels. These cases also produced the highest condensation rates when simulated with the developed model. In the same way, the three configurations that showed no erosion after the durability tests obtained the lowest condensation values in the corresponding CFD cases. 
Finally, a configuration in between of the previous ones in terms of predicted condensation rate showed slight erosion marks in some of the leading edges, implying that there is a threshold of condensation rate from which the erosion is noticeable after 50 hours of testing. The consistency of the results of the comparison has two implications: first, there is a clear correlation between the erosion rate of the compressor wheel and the water condensation rate; second: the proposed model is able to predict the influence of the configuration ( $\mathrm{T}$ joint geometry and working point) on the condensation rate.

Besides, the relevance of using a 3D tool for predicting the condensates can be justified comparing the case with the most condensation rate (first test with geometry i) with the case with geometry v. Both cases were performed under the same operating conditions (mass flow rates, temperatures, humidity content, etc.) but at the end of the durability test the former had produced a noticeable damage on the leading edge while the latter produced no erosion at all. While the 0D perfect mixing model ([13]) provides the same condensation rate figure for both cases, since it only bears the effect of the working point, the proposed 3D approach includes the impact of the geometry, which proves to be significant.

It has to be noted that the criteria used to determine the erosion found on the compressor impeller is qualitative due to the difficulty of assessing this parameter. Examples of the erosion state found after the durability tests can be found in Figures 7, 8 and 9. The case near the damage threshold (Fig. 8) presents an inception of damage on the impeller wheel but without affecting the original shape of the leading edge. Conversely, in the case with erosion (9) the loss of material near the tip of the leading edge is clear.

Taking into account the uncertainties of the numerical model and the experiment, with the quantitative and qualitative comparisons made above, the validity of the model (and the underlying hypotheses) to represent the condensation phenomena is proven.

\subsection{Flow analysis}

In order to present a first approach to why the T-junction geometry may have such a significant impact on the mixing process and the condensation rate, local results of the simulation are exposed next. In Figure 10 the cells where condensation is taking place are highlighted. These cells define an interface between both intake and EGR flows in the first part of the mixing region, then as the flow advances through the duct and mixes, condensation keeps occurring until equilibrium conditions are reached when the whole flow 


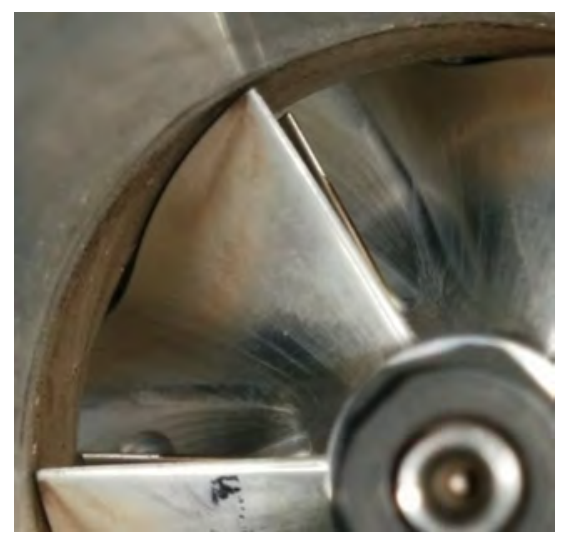

Figure 7: No erosion detected after 50 hours of testing.

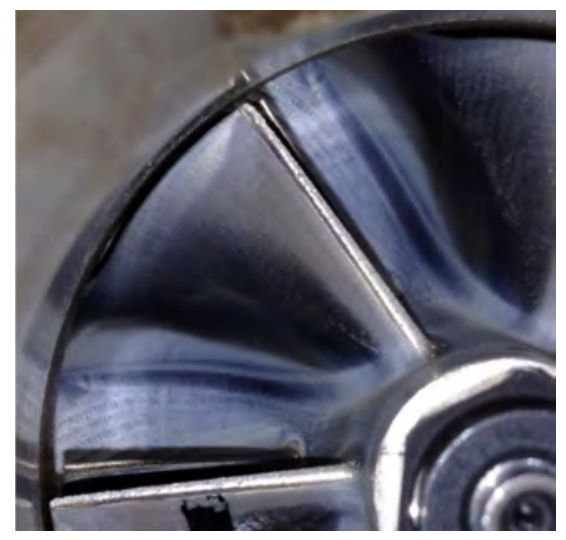

Figure 8: Slight erosion detected after 50 hours of testing.

is saturated. The color field denotes the vapor source term that is vanishing in a given cell.

Once the vapor has condensed, the passive scalar increases to keep tracking of the water as it travels within the flow. Thanks to the passive scalar options available, realistic diffusive and convective properties may be enabled, presenting a homogenization process through the duct. In Figure 11 it is shown this water homogenization process in top and side sections of the valve (see Fig. 3).

Figure 12 depicts the streamlines of the EGR flow to analyze the features of the mixing process. A recirculating region is generated downstream the EGR flow discharge due to the low momentum passing through this area. 


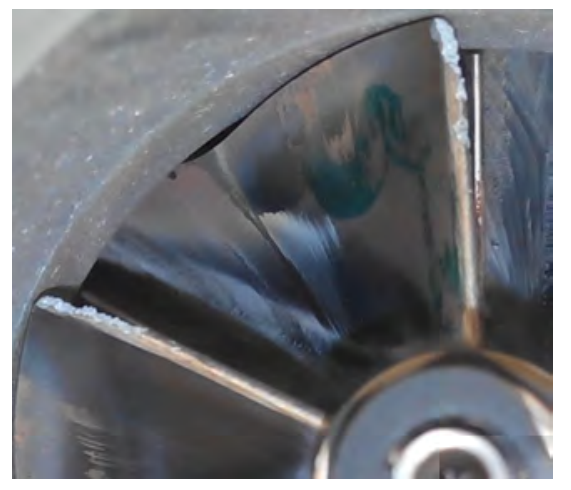

Figure 9: Noticeable erosion detected after 50 hours of testing.

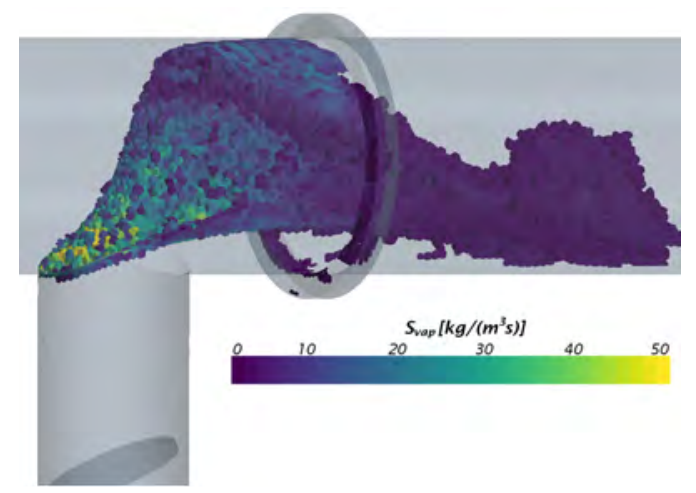

Figure 10: Local condensation region with color field of vapor source value.

Therefore, the EGR flow is moved to the top zone of the duct. In addition, the intake flap generates two symmetric vortices which contribute suctioning the EGR flow and the mixing process. These flow structures are quite stable, so that the mixing keeps occurring continuously as the flow travels downstream.

\section{Conclusions}

A sensitivity study and a validation process have been performed of a verified source term-based condensation model implemented in the commercial 3D-CFD code STAR-CCM+ ${ }^{\circledR}$ [23]. A turbocharger test rig has been set up and instrumented. A testing procedure has been designed to allow a quantitative and qualitative validation of the condensation phenomena, using pressure drop, temperature pattern in a section plane in the mixing region and evaluating the compressor wheel erosion after seven durability tests with 


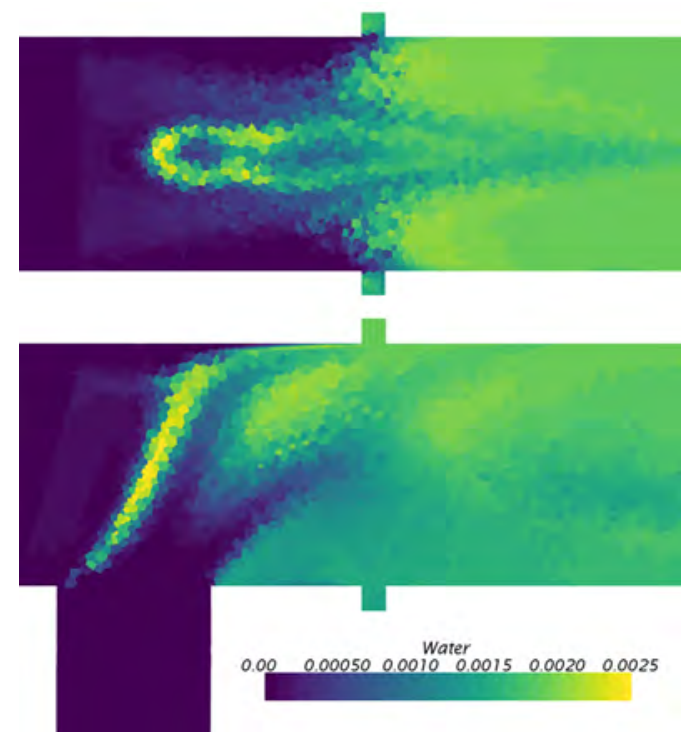

Figure 11: Top and side section planes of water passive scalar fraction field.

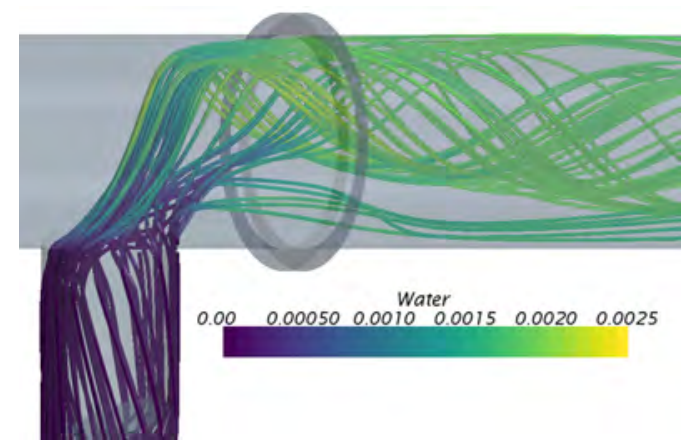

Figure 12: Streamlines of the EGR flow with color field of water passive scalar fraction.

different T-joint configurations and operating conditions. A baseline T-joint geometry has been simulated in order to assess the behavior of the model. The agreement found between the simulated and tested results proved the validity of the model. The sensitivity study added meaningful value to the robustness of the model against different setup variations.

The results showed a significant sensitivity of the mixing flow structures to the intake flap angle. Special attention must be paid to this parameter, since the mixing process controls the condensation rate and hence, the damage of the compressor wheel. The influence of the T-joint geometry was also 
clear thanks to the durability test comparison, highlighting the importance of using a 3D simulation for a proper prediction of the condensates. Finally, a consistent correlation was found between the predicted condensation rate and the erosion of the leading edge, which is meaningful considering that the actual droplet distribution was not being taken into account. Thus, a proper 3D modeling of a particular T-joint configuration is recommended, reproducing its actual geometry as much as possible.

The potential applications of this model can be extended beyond the prediction of condensation in a LR-EGR system. Thus, any kind of problem where, due to psychrometric reasons, vapor condense into liquid water, can be assessed with this model, provided that the hypotheses described in Section 2 are met. Potential fields of application are centrifugal turbines, airconditioning systems or climatic chambers. Further studies may include an evaporation model that complements the condensation model or a wall condensation model. For modeling water droplets generation and trajectories, a different solver would be needed, probably relying on Lagrangian approach.

\section{Acknowledgements}

The authors gratefully acknowledge Joaquín de la Morena and Alberto Racca from GM Global Propulsion Systems-Torino Srl for their support and feedback in the application of the model.

Daniel Tarí is partially supported through contract FPI-S2-2015-1095 of Programa de Apoyo para la Investigación y Desarrollo (PAID) of Universitat Politècnica de València.

\section{References}

[1] J. Serrano, P. Piqueras, R. Navarro, D. Tarí, C. Meano, Development and verification of an in-flow water condensation model for 3D-CFD simulations of humid air streams mixing, Computers \& Fluids 167 (2018) 158 - 165. doi:10.1016/j.compfluid.2018.02.032.

[2] F. Posada, A. Bandivadekar, J. German, Estimated cost of emission control technologies for light-duty vehicles part 1-gasoline, in: SAE Technical Paper, 2013. doi:10.4271/2013-01-0534.

[3] F. Posada, A. Bandivadekar, J. German, Estimated cost of emission control technologies for light-duty vehicles part 2-diesel, in: SAE Technical Paper, 2013. doi:10.4271/2013-01-0539. 


\section{List of Symbols}

$\begin{array}{lll}c_{p} & \text { isobaric specific heat capacity } & \mathrm{J} \cdot \mathrm{kg}^{-1} \cdot \mathrm{K}^{-1} \\ D & \text { diffusion coefficient } & \mathrm{m}^{2} \cdot \mathrm{s}^{-1} \\ \mathrm{fr} & \text { frequency } & \mathrm{Hz} \\ f & \text { additonal terms } & \mathrm{J} \cdot \mathrm{kg}^{-1} \cdot \mathrm{K}^{-1} \\ h & \text { enthalpy } & \mathrm{J} \cdot \mathrm{kg}^{-1} \\ L & \text { latent heat } & \mathrm{m} \\ l & \text { characteristic length } & \mathrm{kg} \cdot \mathrm{s}^{-1} \\ \dot{m} & \text { mass flow rate } & \mathrm{Pa} \\ p & \text { pressure } & \\ S & \text { source term } & \mathrm{K} \\ S t & \text { Strouhal number } & \mathrm{m} \cdot \mathrm{s}^{-1} \\ T & \text { temperature } & \mathrm{m}^{3} \\ U & \text { characteristic velocity } & \mathrm{m} \cdot \mathrm{s}^{-1} \\ V & \text { Volume } & \mathrm{g}_{2} \mathrm{O} \cdot \mathrm{kg}_{\text {air }}^{-1} \\ \vec{u} & \text { velocity } & \mathrm{m} \\ w & \text { specific humidity } & \\ x & \text { coordinate in dominant direction } & \mathrm{m}^{2} \cdot \mathrm{s}^{-1} \\ Y & \text { mass fraction } & \circ \\ \alpha & \text { thermal diffusivity } & \mathrm{Pa} \\ \beta & \text { flap angle } & \mathrm{s} \\ \Delta p & \text { pressure difference } & \% \\ \Delta t & \text { characteristic time } & \% \\ \delta & \text { imbalance of conservation equation } \\ \epsilon & \text { relative difference } & \\ \Gamma_{\varphi} & \text { generic variable } & \mathrm{m}^{2} \cdot \mathrm{s}^{-1} \\ \nu & \text { kinematic viscosity } & \\ \varphi & \text { generic variable } & \mathrm{kg} \cdot \mathrm{m}^{-3} \\ \rho & \text { density } & \end{array}$

[4] J. M. Desantes, J. M. Luján, B. Pla, J. A. Soler, On the combination of high-pressure and low-pressure exhaust gas recirculation loops for improved fuel economy and reduced emissions in high-speed directinjection engines, International Journal of Engine Research 14 (1) (2013) 3-11. doi:10.1177/1468087412437623.

[5] J. Luján, B. Pla, S. Moroz, G. Bourgoin, Effect of low pressure EGR on gas exchange processes and turbocharging of a HSDI engine, in: Pro- 


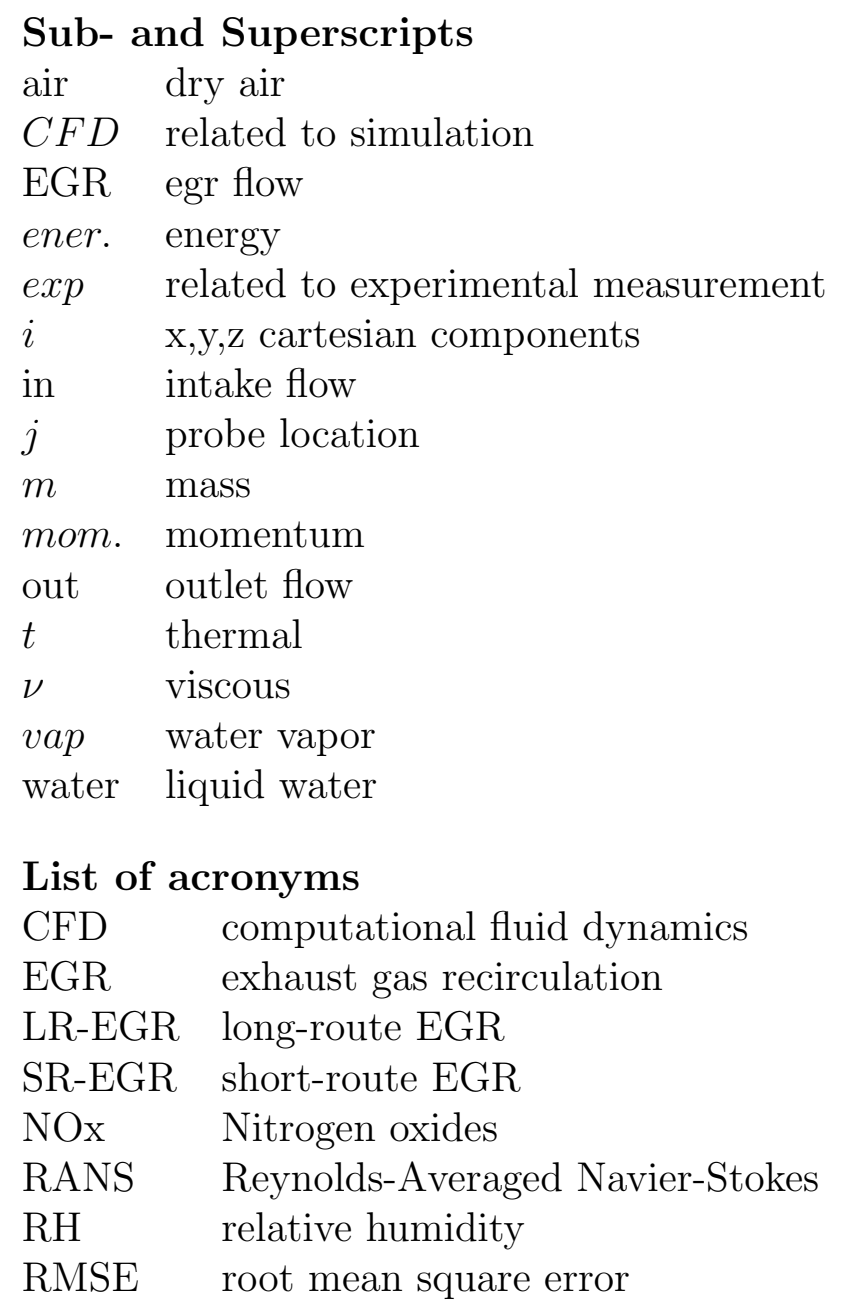

ceedings of the conference on thermo-and fluid-dynamic processes in diesel engines (THIESEL 2008), Valencia, Spain, paper E, Vol. 2, 2008.

[6] J. Benajes, J. R. Serrano, S. Molina, R. Novella, Potential of Atkinson cycle combined with EGR for pollutant control in a HD diesel engine, Energy Conversion and Management 50 (1) (2009) 174 - 183. doi: $10.1016 / \mathrm{j}$.enconman.2008.08.034.

[7] J. M. Luján, H. Climent, R. Novella, M. E. Rivas-Perea, Influence of a low pressure EGR loop on a gasoline turbocharged direct injection 
engine, Applied Thermal Engineering 89 (2015) 432-443. doi:10.1016/ j.applthermaleng.2015.06.039.

[8] A. Cairns, N. Fraser, H. Blaxill, Pre versus post compressor supply of cooled EGR for full load fuel economy in turbocharged gasoline engines, in: SAE Technical Paper, 2008. doi:10.4271/2008-01-0425.

[9] L. Cornolti, A. Onorati, T. Cerri, G. Montenegro, F. Piscaglia, 1D simulation of a turbocharged Diesel engine with comparison of short and long EGR route solutions, Applied Energy 111 (2013) 1-15. doi: 10.1016/j.apenergy.2013.04.016.

[10] J. M. Luján, J. Galindo, J. R. Serrano, B. Pla, A methodology to identify the intake charge cylinder-to-cylinder distribution in turbocharged direct injection diesel engines, Measurement Science and Technology 19 (6) (2008) 065401. doi:10.1088/0957-0233/19/6/065401.

[11] A. Maiboom, X. Tauzia, J.-F. Hétet, Influence of egr unequal distribution from cylinder to cylinder on nox-pm trade-off of a hsdi automotive diesel engine, Applied Thermal Engineering 29 (10) (2009) 2043 - 2050. doi:10.1016/j.applthermaleng.2008.10.017.

[12] N. Ladommatos, S. Abdelhalim, H. Zhao, The effects of exhaust gas recirculation on diesel combustion and emissions, International Journal of Engine Research 1 (1) (2000) 107-126. doi:10.1243/ 1468087001545290 .

[13] J. R. Serrano, P. Piqueras, E. Angiolini, C. Meano, J. De La Morena, On cooler and mixing condensation phenomena in the long-route exhaust gas recirculation line, in: SAE Technical Paper, 2015. doi:10.4271/ 2015-24-2521.

[14] P. Z. John, T. Koka, S. Dayalan, Water droplet erosion simulation of a turbocharger compressor wheel, in: ASME Turbo Expo 2014: Turbine Technical Conference and Exposition, no. GT2014-26974, American Society of Mechanical Engineers, 2014.

[15] Y. Patel, T. Turunen-Saaresti, G. Patel, A. Grönman, Numerical investigation of turbulence modelling on condensing steam flows in turbine cascade, in: ASME Turbo Expo 2014: Turbine Technical Conference 
and Exposition, American Society of Mechanical Engineers, 2014, pp. V01BT27A035-V01BT27A035.

[16] A. Sakowitz, M. Mihaescu, L. Fuchs, Effects of velocity ratio and inflow pulsations on the flow in a T-junction by Large Eddy Simulation, Computers \& Fluids 88 (2013) 374-385. doi:10.1016/j.compfluid.2013. 10.001 .

[17] C. Moses, G. Stein, On the growth of steam droplets formed in a laval nozzle using both static pressure and light scattering measurements, Journal of Fluids Engineering 100 (3) (1978) 311-322. doi:10.1115/1. 3448672 .

[18] M. Grubel, J. Starzmann, M. Schatz, T. Eberle, D. Vogt, Two-phase flow modeling and measurements in low-pressure turbines-part 1: Numerical validation of wet steam models and turbine modeling, 2014. doi:10. 1115/GT2014-25244.

[19] A. Castorrini, A. Corsini, F. Rispoli, P. Venturini, K. Takizawa, T. E. Tezduyar, Computational analysis of wind-turbine blade rain erosion, Computers \& Fluids 141 (Supplement C) (2016) 175 - 183. doi:10. 1016/j.compfluid.2016.08.013.

[20] H. K. Versteeg, W. Malalasekera, An introduction to computational fluid dynamics: the finite volume method, 2nd Edition, Pearson Education Limited, 2007.

[21] F. Crouzet, F. Daude, P. Galon, J.-M. Hrard, O. Hurisse, Y. Liu, Validation of a two-fluid model on unsteady liquidvapor water flows, Computers \& Fluids 119 (2015) 131-142. doi:10.1016/j.compfluid. 2015. 06.035.

[22] Y. Wang, H. Liu, D. Liu, S. Yuan, J. Wang, L. Jiang, Application of the two-phase three-component computational model to predict cavitating flow in a centrifugal pump and its validation, Computers \& Fluids 131 (2016) 142-150. doi:10.1016/j.compfluid.2016.03.022.

[23] CD-adapco, STAR-CCM+, release version 9.04.011 Edition (2014). URL http://www.cd-adapco.com 
[24] A. H. Yousif, A. M. Al-Dabagh, R. C. Al-Zuhairy, Non-equilibrium spontaneous condensation in transonic steam flow, International Journal of Thermal Sciences 68 (2013) 32 - 41. doi:https://doi.org/10.1016/ j.ijthermalsci.2013.01.002.

[25] Psychrometric Chart - Structure and Application, Siemens Building Technologies Group, 2014. URL www. siemens .com

[26] D. C. Shallcross, Psychrometric charts for water vapour in natural gas, Journal of Petroleum Science and Engineering 61 (1) (2008) 1-8. doi: $10.1016 / \mathrm{j}$.petrol.2007.10.002.

[27] J. Luján, V. Bermúdez, J. R. Serrano, C. Cervelló, Test bench for turbocharger groups characterization, SAE Technical Paper 2002-01-0163. doi:10.4271/2002-01-0163.

[28] M. Tancrez, J. Galindo, C. Guardiola, P. Fajardo, O. Varnier, Turbine adapted maps for turbocharger engine matching, Experimental Thermal and Fluid Science 35 (1) (2011) 146-153. doi:10.1016/j. expthermflusci.2010.07.018.

[29] A. Sakowitz, M. Mihaescu, L. Fuchs, Turbulent flow mechanisms in mixing T-junctions by Large Eddy Simulations, International Journal of Heat and Fluid Flow 45 (2014) 135-146. doi:10.1016/j. ijheatfluidflow.2013.06.014.

[30] D. C. Wilcox, Turbulence Modeling for CFD (Hardcover), 3rd Edition, Dcw Industries Inc., 2006.

[31] W. Jones, B. Launder, The prediction of laminarization with a twoequation model of turbulence, International Journal of Heat and Mass Transfer 15 (2) (1972) 301-314. doi:10.1016/0017-9310 (72) 90076-2.

[32] J. Costa, L. Oliveira, D. Blay, Test of several versions for the $\mathrm{k}-\varepsilon$ type turbulence modelling of internal mixed convection flows, International Journal of Heat and Mass Transfer 42 (23) (1999) 4391-4409. doi: 10.1016/S0017-9310(99)00075-7. 
[33] J. Galindo, R. Navarro, D. Tarí, G. García-Olivas, Centrifugal compressor influence on condensation due to Long Route-Exhaust Gas Recirculation mixing, Applied Thermal Engineering 144 (2018) 901 - 909. doi:https://doi.org/10.1016/j.applthermaleng.2018.09.005.

[34] Ferziger, J.H. and Perić, M., Computational Methods for Fluid Dynamics, 3rd Edition, Springer, 2002.

[35] J. M. Chen, Y.-C. Fang, Strouhal numbers of inclined flat plates, Journal of wind engineering and industrial aerodynamics 61 (2) (1996) 99-112. doi : 10.1016/0167-6105(96)00044-X.

[36] F. R. Menter, Two-equation eddy-viscosity turbulence models for engineering applications, AIAA journal 32 (8) (1994) 1598-1605. doi: 10.2514/3.12149.

[37] J. Galindo, S. Hoyas, P. Fajardo, R. Navarro, Set-up analysis and Optimization of CFD Simulations for Radial Turbines, Engineering Applications of Computational Fluid Mechanics 7 (4) (2013) 441-460. doi:10.1080/19942060.2013.11015484. 